\title{
Analysis of gene expression array in TSC2-deficient AML cells reveals IRF7 as a pivotal factor in the Rheb/mTOR pathway
}

\author{
V Makovski ${ }^{1}$, J Jacob-Hirsch ${ }^{2}$, C Gefen-Dor ${ }^{2}$, B Shai ${ }^{3}$, M Ehrlich ${ }^{3}$, G Rechavi ${ }^{2,4}$ and Y Kloog ${ }^{1}$
}

Mutations in tuberous sclerosis (TSC) genes cause the genetic disorder TSC, as well as other neoplasms, including lymphangioleiomyomatosis (LAM) and angiomyolipomas (AMLs). AMLs are benign renal tumors occur both in sporadic LAM and in TSC. As they carry the same mutations, AML cell lines serve as a model for TSC and LAM. Rheb/mammalian target of rapamycin complex 1 (mTORC1) pathway is chronically activated in TSC-deficient cells, and this activation can be diminished using the appropriate inhibitors. Rapamycin (sirolimus) is a known specific inhibitor of mTORC1, whereas S-trans,trans-farnesylthiosalicylic acid (FTS; salirasib) has been shown to inhibit Rheb. To examine the effect of the Rheb/mTOR inhibition pathway, we used human TSC2-deficient AML cells, derived from a LAM patient. FTS indeed inhibited Rheb in these cells and attenuated their proliferation. After comparative treatments with FTS or rapamycin or by re-expression of TSC2, we carried out a gene array analysis. This yielded a substantial number of commonly altered genes, many of which we identified as downstream targets of the interferon (IFN) regulatory factor 7 (IRF7) transcription factor, a central activator of the IFN type 1 immune response. Furthermore, nuclear localization of IRF7 was impaired by each of the three treatments. Interestingly, the phenomena seen on FTS or rapamycin treatment were selective for TSC2-deficient cells. Moreover, knockdown of IRF7 by siRNA mimicked the decrease in number of the abovementioned genes and also inhibited AML cell proliferation. Altogether, these findings support FTS as a potential treatment for TSC and its related pathologies and IRF7 as a novel target for treatment.

Cell Death and Disease (2014) 5, e1557; doi:10.1038/cddis.2014.502; published online 4 December 2014

Tuberous sclerosis (TSC) is a genetic disease characterized by neurological disorders, as well as by benign tumors in various organs and is caused by a germline inactivating mutation in one of the TSC genes - TSC1 or TSC2. ${ }^{1}$ About $40 \%$ of women with TSC will develop pulmonary lymphangioleiomyomatosis (LAM), which is a lethal disease affecting mainly women of childbearing age. ${ }^{2}$ It is characterized by proliferation and migration of smooth muscle cells from an unknown source into the lung, resulting in the obstruction of small airways and lymphatic vessels and leading to cystic parenchymal destruction and eventually death. ${ }^{3-5}$ There are two types of LAM: sporadic LAM (S-LAM) and LAM associated with TSC. ${ }^{2}$

About $80 \%$ of TSC patients and $40 \%$ of patients with S-LAM will develop renal angiomyolipomas (AMLs), benign kidney tumors containing fatty tissue, smooth muscle cells and dysplastic blood vessels. ${ }^{6-8}$ AML cells closely resemble LAM cells, as both carry inactivating mutations in either the TSC1 or the TSC2 gene., ${ }^{7,9,10}$ Previous studies raised the hypothesis that renal AML cells can generate pulmonary LAM by metastasizing into the lung. ${ }^{7,11}$

The protein products of TSC genes act as GTPaseactivating proteins for Rheb; consequently, loss of TSC1 or
TSC2 expression leads to hyperactivation of the Rheb/mTOR pathway. ${ }^{12}$ Rheb belongs to the Ras superfamily of GTPases and terminates in a farnesylated CAAX motif. ${ }^{13}$ Our group has shown that activated Rheb-GTP is inhibited by farnesylthiosalicylic acid (FTS, salirasib) in TSC2-deficient cells of Eker rat leiomyoma (ELT3) cells. ${ }^{14}$ FTS, which was originally designed to mimic the farnesyl cysteine moiety of the $\mathrm{COOH}$ terminus of Ras, is currently undergoing clinical trials for cancer treatment. ${ }^{15}$ Rheb in its active form activates mammalian target of rapamycin complex 1 (mTORC1), a key regulator of protein translation, metabolism and cell proliferation. ${ }^{16}$ Rapamycin (sirolimus), a known inhibitor of mTORC1, has already been tested in LAM patients in the Multicenter International LAM Efficacy of Sirolimus (MILES) trial and has shown promising results that include improvement in lung function and alleviation of symptoms. ${ }^{17}$

Interferon (IFN) regulatory factors (IRFs) are a family of transcription factors that regulate the immune response to viral invasion by regulating IFN-induced immune response. They also have important roles in immune cell development, inflammation and oncogenesis. ${ }^{18}$ Mammalian cells harbor nine known members of the IRF family (IRF1-IRF9). IRF7, in conjunction with IRF3, is the main factor in regulation of the

${ }^{1}$ Department of Neurobiology, The George S Wise Faculty of Life Sciences, Tel-Aviv University, Tel-Aviv, Israel; ${ }^{2}$ Department of Pediatric Hematology - Oncology, Safra Children's Hospital, Sheba Medical Center, Tel Hashomer, Israel; ${ }^{3}$ Department of Cell Research and Immunology, The George S Wise Faculty of Life Sciences, Tel-Aviv University, Tel-Aviv, Israel and ${ }^{4}$ Sackler Faculty of Medicine, Tel-Aviv University, Tel-Aviv, Israel

*Corresponding author: Y Kloog, Department of Neurobiology, The George S Wise Faculty of Life Sciences, Tel-Aviv University, Tel-Aviv 69978, Israel. Tel: +972 3640 9699; Fax: +972 3640 7643; E-mail: kloog@post.tau.ac.il

Abbreviations: TSC, tuberous sclerosis; LAM, lymphangioleiomyomatosis; AML, angiomyolipoma; FTS, farnesylthiosalicylic acid; IFN, interferon; IRF7, interferon regulatory factor 7

Received 15.7.14; revised 07.10.14; accepted 13.10.14; Edited by M Agostini 
a

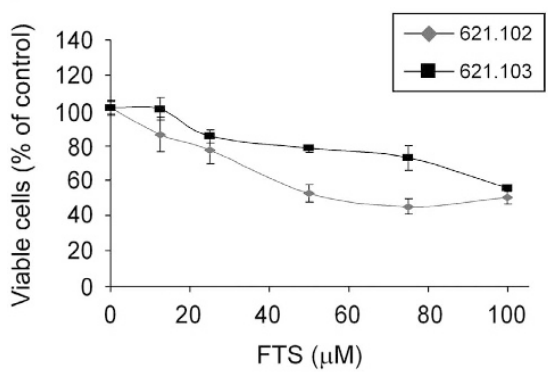

b

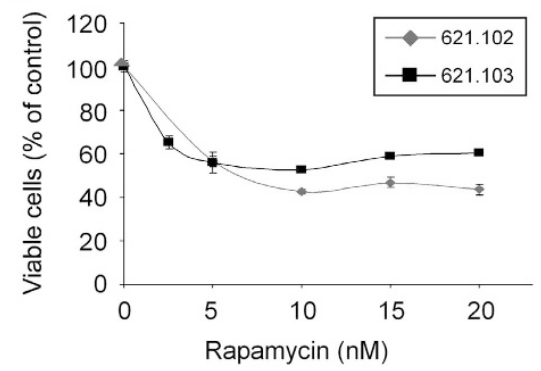

C

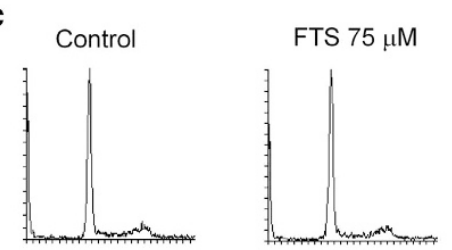

Rapamycin $10 \mathrm{nM}$

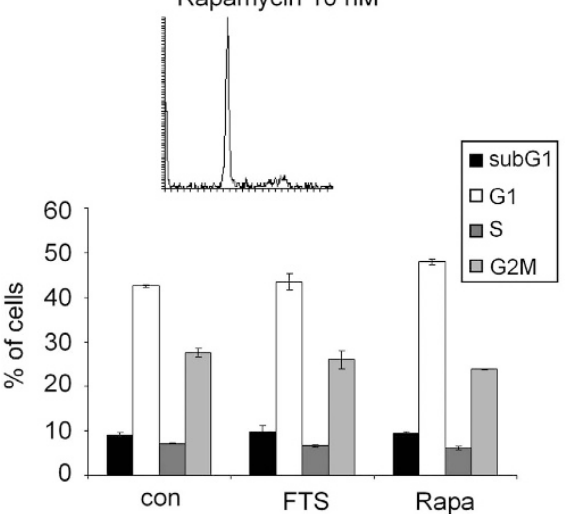

d

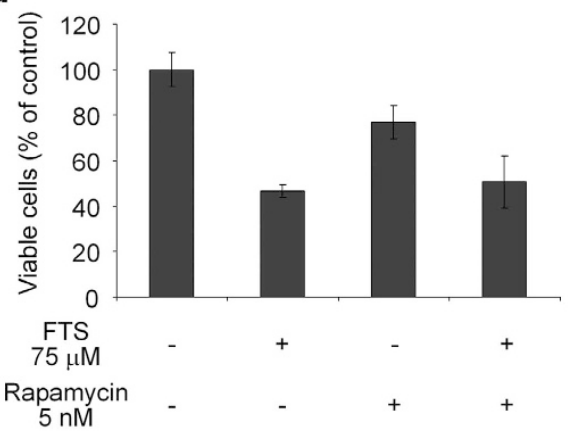

e
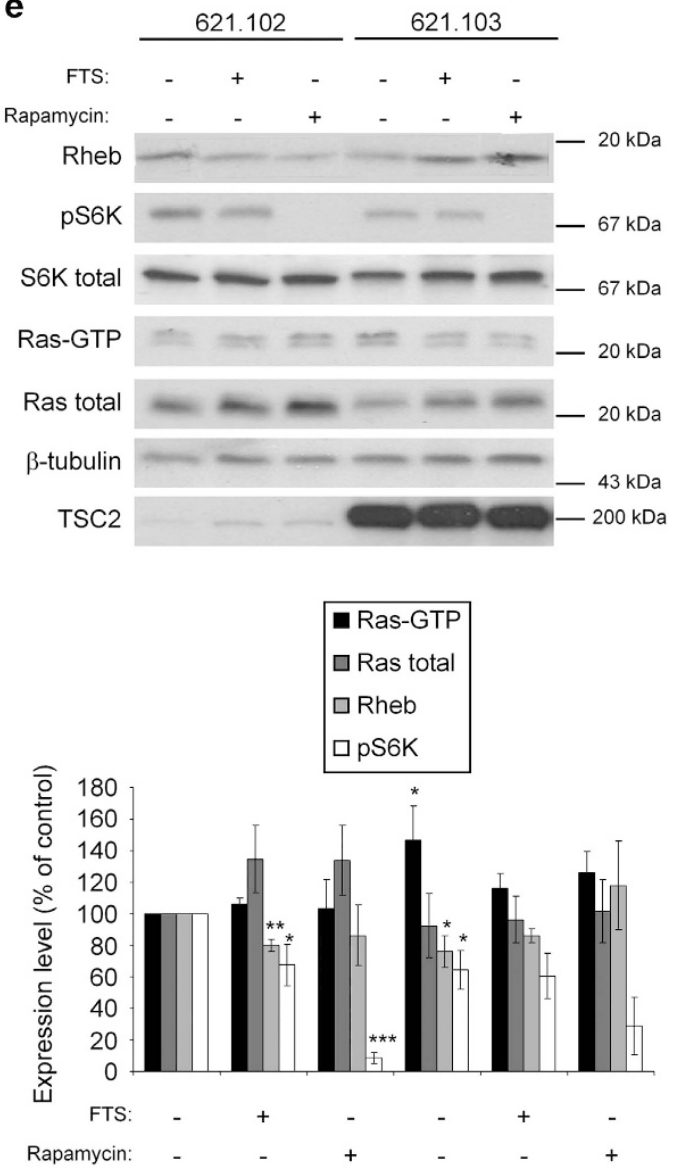

Figure 1 FTS inhibits AML cell proliferation and the Rheb/mTOR pathway, similarly to rapamycin. (a) The 621.102 (TSC2-deficient) and 621.103 (TSC2-re-expressing) AML cells were seeded and grown for 6 days in the absence and in the presence of the indicated concentrations of $\mathrm{FTS}$, or with $0.1 \% \mathrm{Me}_{2} \mathrm{SO}_{4}$ (control). Cells were directly counted and a typical inhibition curve is shown (means \pm S.E.M., $n=3$ ). (b) The 621.102 and 621.103 cells were seeded and grown for 6 days in the absence and in the presence of the indicated concentrations of rapamycin. Cells were directly counted and a typical inhibition curve is shown (means \pm S.E.M., $n=3$ ). (c) The 621.102 cells were seeded and grown for 2 days in the absence and in the presence of $75 \mu \mathrm{M} \mathrm{FTS}$ or $10 \mathrm{nM}$ rapamycin or $0.1 \% \mathrm{Me}_{2} \mathrm{SO}_{4}$ (control). Cells then were fixed, PI stained and subjected to FACS for cell cycle analysis (see Materials and methods section). Typical histograms are shown in the upper panel. The quantification of the different cell cycle phases is shown in the lower panel. No significant difference was observed after FTS or rapamycin treatment. (d) The 621.102 cells were seeded and grown for 6 days in the absence and in the presence of the indicated concentration of both $\mathrm{FTS}$ and rapamycin, or with $0.1 \% \mathrm{Me}_{2} \mathrm{SO}_{4}$ (control). Cells were directly counted and the percentages of live cells are presented. (e) TSC2-deficient 621.102 and TSC2-re-expressing 621.103 cells were treated for 2 days with $75 \mu \mathrm{M}$ FTS or $10 \mathrm{nM}$ rapamycin or $0.1 \% \mathrm{Me}_{2} \mathrm{SO}_{4}$ (control). Rheb, p-389 S6K, total S6K, Ras-GTP, Ras, $\beta$-tubulin and TSC2 were assayed by immunoblotting, as described in Materials and methods section. Statistical analyses of immunoblots from three experiments are shown in the lower panel $\left(n=3,{ }^{*} P<0.05,{ }^{* *} P<0.01,{ }^{* *} P<0.001\right)$

IFN type 1 response (IFNa/ $\beta$ ). In its inactive state, IRF7 is localized in the cytoplasm. Following pathogen invasion it is activated by phosphorylation, and this leads to its translocation into the nucleus. As a transcription factor, IRF7 activates the transcription of IFN-stimulated genes, as well as small amounts of type 1 IFN (IFNa/ $\beta$ ), and the latter leads to additional transcription of IRF7 via activation of the JAK/STAT signaling cascade. This positive feedback loop is essential for 
the elimination of viral invasion ${ }^{19}$ and also has antitumor and immunomodulatory functions. ${ }^{20}$ The Rheb/mTOR pathway was reported to participate in the activation of IRF7. ${ }^{21}$

In this study, we investigated the effect of FTS on human AML cells, which were shown to serve as a model for LAM. ${ }^{7}$ Using a gene array method, we demonstrate that FTS, by targeting Rheb, can inhibit the function of IRF7 in AML cells, thereby mimicking the effects of rapamycin and re-expression of TSC2.

\section{Results}

FTS and rapamycin inhibit proliferation of TSC2-null 621 cells by inhibiting the Rheb/mTORC1 signaling pathway. AMLs are benign kidney tumors containing smooth muscle cells, blood vessels and fat cells. ${ }^{6}$ These tumors are used to develop cell lines that can serve as models for LAM, as it is difficult to establish cell lines from pulmonary LAM cells. ${ }^{7}$ Here we used the AML cell line, 621 , which is derived from a LAM patient and is deficient in TSC2. ${ }^{7}$ Having already shown that FTS inhibits the growth of TSC2deficient rat ELT3 cells and inhibits Rheb but not Ras in those cells, ${ }^{14}$ we now wanted to substantiate those observations in a human model.

For this purpose, we used the TSC2-deficient 621.102 and the TSC2-re-expressing 621.103 cells, which are stably transfected with an empty vector and the TSC2 vector, respectively. ${ }^{22}$ First, we examined the impact of FTS on growth of the 621.102 and 621.103 cell lines. Cells were treated with the indicated doses of FTS for 6 days and were then counted (Figure 1a). We found that FTS inhibited the proliferation of 621.102 cells in a dose-dependent manner, with an average $\mathrm{IC}_{50}$ of $53 \pm 3.3 \mu \mathrm{M}(n=3)$. The 621.103 cells were less sensitive to FTS treatment with an average $\mathrm{IC}_{50}$ of $90 \pm 5.7 \mu \mathrm{M}(n=3)$, indicating that FTS is selective to the TSC2-deficient cells as shown previously. ${ }^{14}$ In an accompanying experiment, we treated 621.102 cells for 6 days with the mTORC1 inhibitor rapamycin (Figure 1b), which yielded an $I_{50}$ of $5.5 \pm 2.3 \mathrm{nM}(n=3)$. Similar to their response to FTS, 621.103 TSC2-expressing cells were less sensitive to rapamycin with an average $\mathrm{IC}_{50}$ of $17.5 \pm 2.5 \mathrm{nM}(n=3)$.

In order to show the mechanism of cell growth inhibition by the two drugs, we performed cell cycle analysis of the 621.102 cells after treatment with FTS or rapamycin (Figure 1c). The experiment showed that there was no significant difference in the percentage of subG1 population of the 621.102 cells after treatment with FTS or rapamycin, which means that neither of the drugs induces cell death. This was also strengthened by cell counting experiment with Trypan blue (data not shown). No difference was observed in the percentage of other cell cycle populations, indicating that both drugs do not cause cell cycle arrest in any particular stage.

We then performed an additional experiment using a combination of $75 \mu \mathrm{M}$ FTS and $5 \mathrm{nM}$ rapamycin on 621.102 cells (Figure 1d). Although FTS alone and rapamycin alone inhibited cell growth by $53 \pm 3 \%$ and $23 \pm 7 \%$ respectively, their combined treatment yielded an inhibition of only $50 \pm 12 \% \quad(n=4)$. This showed that neither drug has any additive or synergistic effect, supporting our previous observation that FTS inhibits Rheb and that it does so by acting through the same pathway as rapamycin.

Next, we wanted to confirm that, as we showed previously in rat ELT3 cells, ${ }^{14}$ the observed inhibition of growth by FTS was attributable to inhibition of Rheb and not Ras. The cells were seeded in $10-\mathrm{cm}$ plates, treated with $75 \mu \mathrm{M}$ FTS or $10 \mathrm{nM}$ rapamycin, and lysed 2 days later. Samples were then immunoblotted with the indicated antibodies to Ras, Rheb and the downstream Rheb target pS6K. As shown in Figure 1e, FTS downregulated Rheb and its downstream target S6K (p-T389) in the 621.102 cells to the levels of $80 \pm 4 \%$ and $67.5 \pm 13.2 \%$ of control, respectively $(n=3$, $P<0.05)$. The levels of active Ras-GTP and total Ras, however, did not change significantly $(106 \pm 4.1 \%$ and $135 \pm 21.5 \%$, respectively; $n=3, P>0.05$; Figure $1 \mathrm{e})$. These results are consistent with those we obtained in TSC2deficient rat ELT3 cells. ${ }^{14}$ We also found here that rapamycin almost completely abolished the level of phosphorylated S6K, reducing it to $8.6 \pm 3.9 \% \quad(n=3, P<0.05)$ but did not significantly change the levels of Rheb or Ras-GTP. Re-expression of TSC2 mimicked the effects of FTS, reducing the levels of Rheb and pS6K to $76.3 \pm 10 \%$ and $64.4 \pm 12.2 \%$ respectively $(n=3, P<0.05)$. Interestingly, TSC2 re-expression raised the level of active Ras-GTP to $146.8 \pm 21.7 \%(n=3, P<0.05)$. FTS and rapamycin increased the level of Rheb expression in 621.103 cells, the reason for that may be the involvement of other compensation mechanisms after re-expression of TSC2.

It should be noted that FTS treatment was selective only for the 621.102 TSC2-deficient cells. In the 621.103 TSC2re-expressing cells, the treatment did not change the level of either Rheb or pS6K as compared with the untreated cells. As to rapamycin, it was shown to inhibit the phosphorylation of S6K also in the 621.103 cells (Figure 1e). We assume that the reason for the difference between $\mathrm{FTS}$ and rapamycin is that rapamycin is very specific to $\mathrm{mTORC} 1$, whereas FTS inhibits all farnesylated GTPases, including Ras. When Rheb-GTP levels are high, the steady state is shifted toward Rheb inhibition. Upon TSC2 re-expression, Rheb-GTP levels decrease, whereas Ras-GTP is upregulated and the steady state is shifted toward Ras inhibition in this case. This is possibly the reason for the observed selective effect of FTS.

The fact that FTS can inhibit the growth of the AML cell line (which serves as an in vitro human model for LAM) and inhibits Rheb in these cells supports our suggestion that FTS should be considered as a possible treatment for LAM.

\section{Impact of FTS, rapamycin and TSC2 on gene expression} in AML cells. Having now recapitulated the impact of FTS on Rheb in TSC2-deficient human cells (Figure 1), our next task was to compare the effects of FTS and rapamycin treatment and TSC2 re-expression on a larger scale. For this purpose, we performed a gene array analysis on the AML cell lines. We seeded 621.102 and 621.103 cells in $10-\mathrm{cm}$ plates and treated them with $75 \mu \mathrm{M}$ FTS or $10 \mathrm{nM}$ rapamycin for $48 \mathrm{~h}$. As rapamycin is known to specifically inhibit mTORC1, which is a direct downstream target of Rheb, ${ }^{23}$ we used it as a positive control. We then resuspended the cells in TRIzol for RNA extraction and performed gene array profiling as described in Materials and methods section (Figure 2a). 


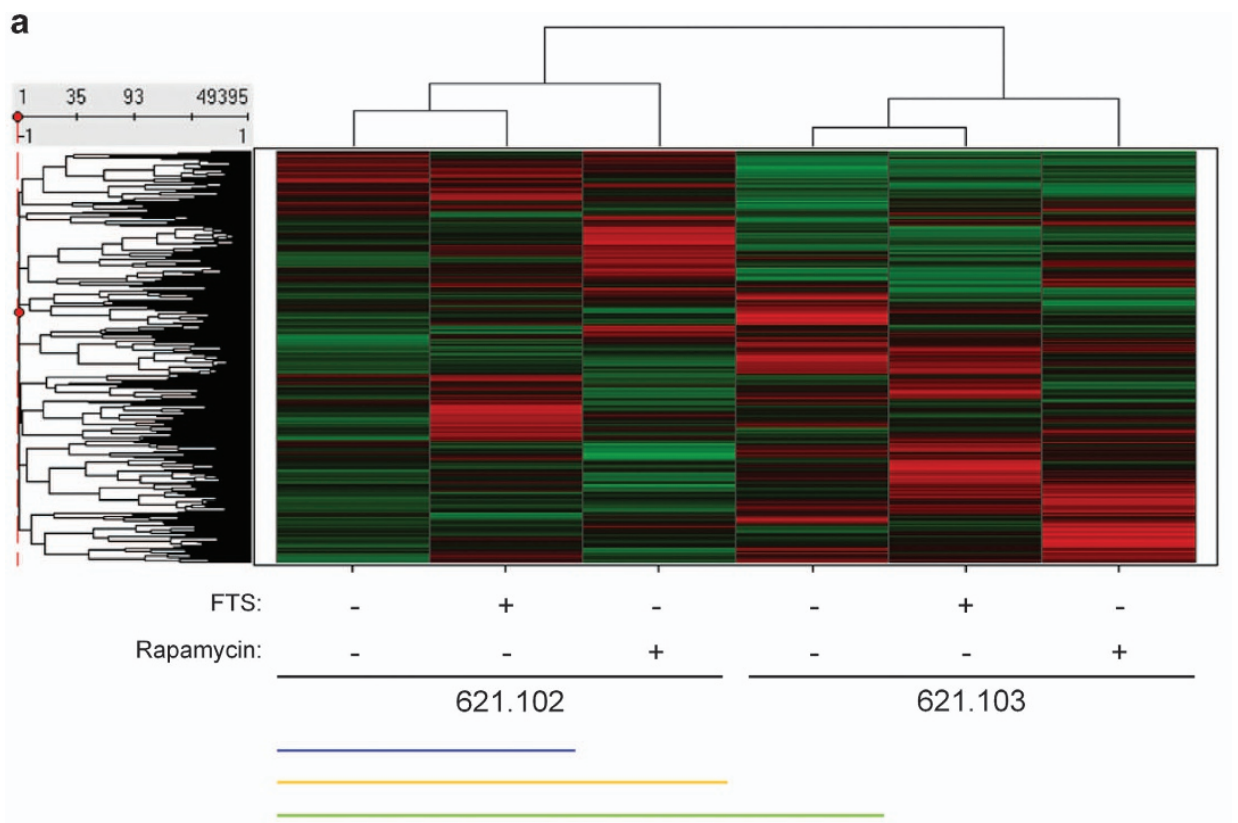

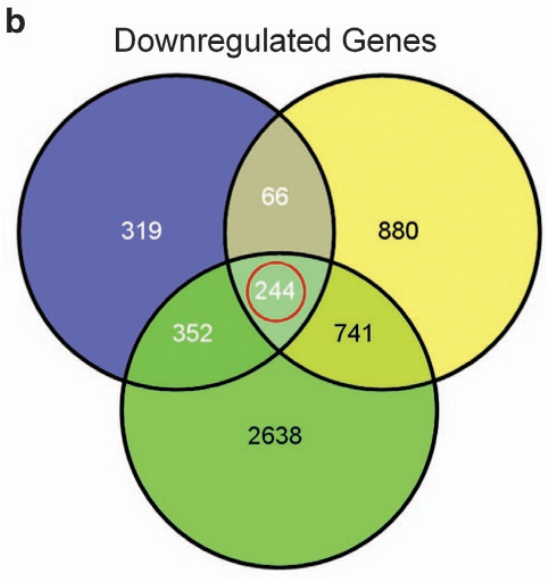

FTS Rapamycir

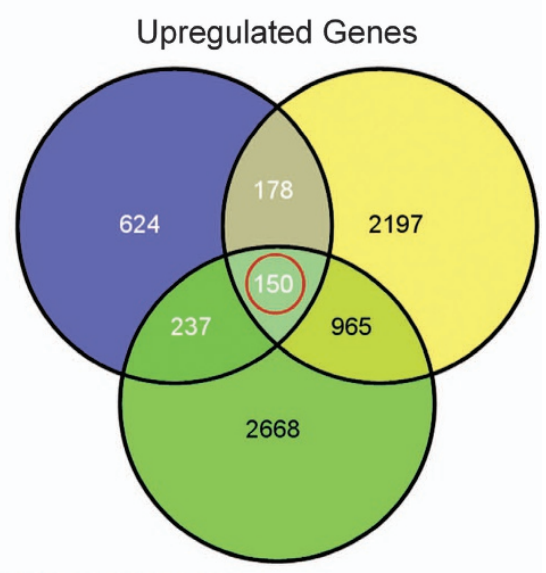

TSC2 re-expression

Figure 2 Comparative gene array analysis of 621.102 and 621.103 cells treated with FTS or rapamycin. (a) Hierarchical clustering of 49395 probes, depicted in a dendrogram. Red, high relative expression; green, low relative expression. Genes are shown in columns; samples are shown in rows. (b) Venn diagram of the genes downregulated or upregulated by FTS versus control in 621.102 cells (blue), by rapamycin versus control in 621.102 cells (yellow) and by TSC2 re-expression in 621.103 control cells versus 621.102 control cells (green). The genes in red circles were analyzed further

Using a 1.5-fold change in gene expression level as a criterion, we then analyzed only the group of genes that were either downregulated (244 genes; Figure $2 b$ ) or upregulated (150 genes) under the three conditions (FTS treatment, rapamycin treatment and TSC2 re-expression; Figure 2b). This was done to restrict the size of the group of analyzed genes to that related to the Rheb/mTOR pathway.

FTS affects the expression of genes involved in the IFN type 1 immune response. We used the DAVID Functional Annotation Clustering tool to analyze the common genes identified above. In the initial analysis, we found that the most prominent groups of genes were those associated with response to virus, regulation of cell death and defense response (Table 1). These results are unique when compared with a variety of gene expression profiles that we obtained previously, with and without FTS, in different cancer cells. ${ }^{24-26}$ FTS is shown here for the first time to affect genes involved in the immune response. Ingenuity software (QIAGEN, Redwood City, CA, USA) showed that a large proportion of the altered genes belong to the IFN type 1 signaling pathway (Figure 3).

To validate the results of the gene array, we randomly chose nine genes from the abovementioned prominent groups with relatively high expression levels so as to make it easier to validate using qRT-PCR (Table 2). Cells were seeded and treated in the same way as for the gene array and were then subjected to quantitative RT-PCR with specific primers, as described in Materials and methods section. We found that the qRT-PCR results indeed correlated with the gene array results. 
Table 1 Biological processes most enriched in the analyzed genes

\begin{tabular}{|c|c|c|c|}
\hline Term & Count & $\%$ & $P$-value \\
\hline GO:0009615 - response to virus & 10 & 2.53 & 0.0009 \\
\hline GO:0010941 - regulation of cell death & 34 & 8.61 & 0.0010 \\
\hline GO:0048518 - positive regulation of biological process & 68 & 17.22 & 0.0010 \\
\hline GO:0006793 - phosphorus metabolic process & 38 & 9.62 & 0.0016 \\
\hline GO:0006952 - defense response & 27 & 6.84 & 0.0019 \\
\hline GO:0009611 - response to wounding & 24 & 6.08 & 0.0025 \\
\hline GO:0048002 - antigen processing and antigen peptide presentation & 5 & 1.27 & 0.0036 \\
\hline GO:0048522 - positive regulation of cellular process & 60 & 15.19 & 0.0044 \\
\hline GO:0045087 - innate immune response & 10 & 2.53 & 0.0045 \\
\hline GO:0051270 - regulation of cell motion & 12 & 3.04 & 0.0049 \\
\hline GO:0019538 - protein metabolic process & 84 & 21.27 & 0.0060 \\
\hline GO:0032879 - regulation of localization & 25 & 6.33 & 0.0071 \\
\hline GO:0051272 - positive regulation of cell motion & 8 & 2.03 & 0.0072 \\
\hline GO:0043069 - negative regulation of programmed cell death & 17 & 4.30 & 0.0085 \\
\hline GO:0060548 - negative regulation of cell death & 17 & 4.30 & 0.0088 \\
\hline GO:0040012 - regulation of locomotion & 11 & 2.78 & 0.0129 \\
\hline GO:0030334 - regulation of cell migration & 10 & 2.53 & 0.0158 \\
\hline GO:0051707 - response to other organism & 14 & 3.54 & 0.0162 \\
\hline GO:0040017 - positive regulation of locomotion & 7 & 1.77 & 0.0249 \\
\hline GO:0006897 - endocytosis & 11 & 2.78 & 0.0300 \\
\hline GO:0010324 - membrane invagination & 11 & 2.78 & 0.0300 \\
\hline GO:0006935 - chemotaxis & 9 & 2.28 & 0.0308 \\
\hline GO:0042330 - taxis & 9 & 2.28 & 0.0308 \\
\hline GO:0002682 - regulation of immune system process & 16 & 4.05 & 0.0318 \\
\hline GO:0006082 - organic acid metabolic process & 21 & 5.32 & 0.0330 \\
\hline GO:0001666 - response to hypoxia & 8 & 2.03 & 0.0343 \\
\hline GO:0042180 - cellular ketone metabolic process & 21 & 5.32 & 0.0363 \\
\hline GO:0042127 - regulation of cell proliferation & 27 & 6.84 & 0.0381 \\
\hline GO:0010942 - positive regulation of cell death & 17 & 4.30 & 0.0423 \\
\hline GO:0070482 - response to oxygen levels & 8 & 2.03 & 0.0433 \\
\hline GO:0044093 - positive regulation of molecular function & 21 & 5.32 & 0.0487 \\
\hline
\end{tabular}

Ease score $<0.05$

Compared with 621.102, the expression levels of the indicated genes were downregulated (Figure 4a) or upregulated (Figure $4 \mathrm{~b}$ ) by treatment with FTS or rapamycin in the 621.102 cells and by TSC2 re-expression in the 621.103 cells, as anticipated from the gene array. We can see, as expected, the increase in TSC2 expression in the 621.103 cells (Figure 4b). Consistently with the gene array results, treatment with FTS or rapamycin did not affect expression levels in the 621.103 cells. These results indicated that both FTS and rapamycin treatment are selective only for the TSC2deficient cells, a finding compatible with our results shown here in Figure 1d.

FTS, rapamycin and re-expression of TSC2 inhibit the IRF7 transcription factor. An 'upstream regulator' is a protein that is not itself altered in the gene array profiles, but many of its downstream targets are altered. Using the Ingenuity software, we obtained a list of upstream regulators, the most significant being the transcription factor IRF7 (Figure 5). We assayed the mRNA and protein levels of IRF7 under the different conditions (FTS or rapamycin treatment or TSC2 re-expression) using qRT-PCR and western immunoblotting (data not shown). We did not observe any substantial effects of FTS or rapamycin on the mRNA or protein levels of IRF7, which pointed to the involvement of some other mechanism of IRF7 inhibition.

As IRF7 is a transcription factor that operates in the nucleus, ${ }^{19}$ we wanted to see whether FTS could displace
IRF7 from the nucleus. Cells were seeded and treated as described in the previous experiment, and were then fixed with 4\% PFA and stained with anti-IRF7 Ab (red fluorescence) or Hoechst (blue fluorescence) to label the nuclei (Figure 6a). Using confocal microscopy, we then quantified the proportion of the nuclear fraction of IRF7 inside the imaged cells (Figure 6c). The results showed that, compared with control, treatment with FTS or rapamycin or re-expression of TSC2 significantly decreased the nuclear fraction of IRF7 (to $67.5 \pm 2.8 \%, 88.8 \pm 3.6 \%$ or $84.2 \pm 3.2 \%$, respectively, $P<0.05, n=30$; Figures $6 \mathrm{a}$ and $6 \mathrm{c}$ ).

In addition, we also performed nuclear fractionation of 621.102 and 621.103 cell lysates. Cells were seeded and treated as described in the previous experiment, and were then lysed with cytosolic buffer and fractionated to nuclear and cytosolic fractions (see Materials and methods section). The fractions were subjected to western immunoblots with IRF7, $\beta$-tubulin and PARP antibodies. $\beta$-Tubulin was used as a cytosolic marker and PARP was used as a nuclear marker to show the quality of fraction separation (Figure 6b). Quantification of nuclear/cytosolic ratio of IRF7 showed a significant decrease in IRF7 nuclear localization after FTS or rapamycin treatment or TSC2 re-expression (to $67.5 \pm 2.8 \%, 88.8 \pm 3.6 \%$ or $84.2 \pm 3.2 \%$, respectively, $P<0.05, n=3$; Figure $6 \mathrm{~d}$ ).

Knockdown of IRF7 mimics the effects of Rheb/mTORC1 inhibition. To further establish IRF7 as an important factor in AML cell function, we used siRNA against IRF7 to 


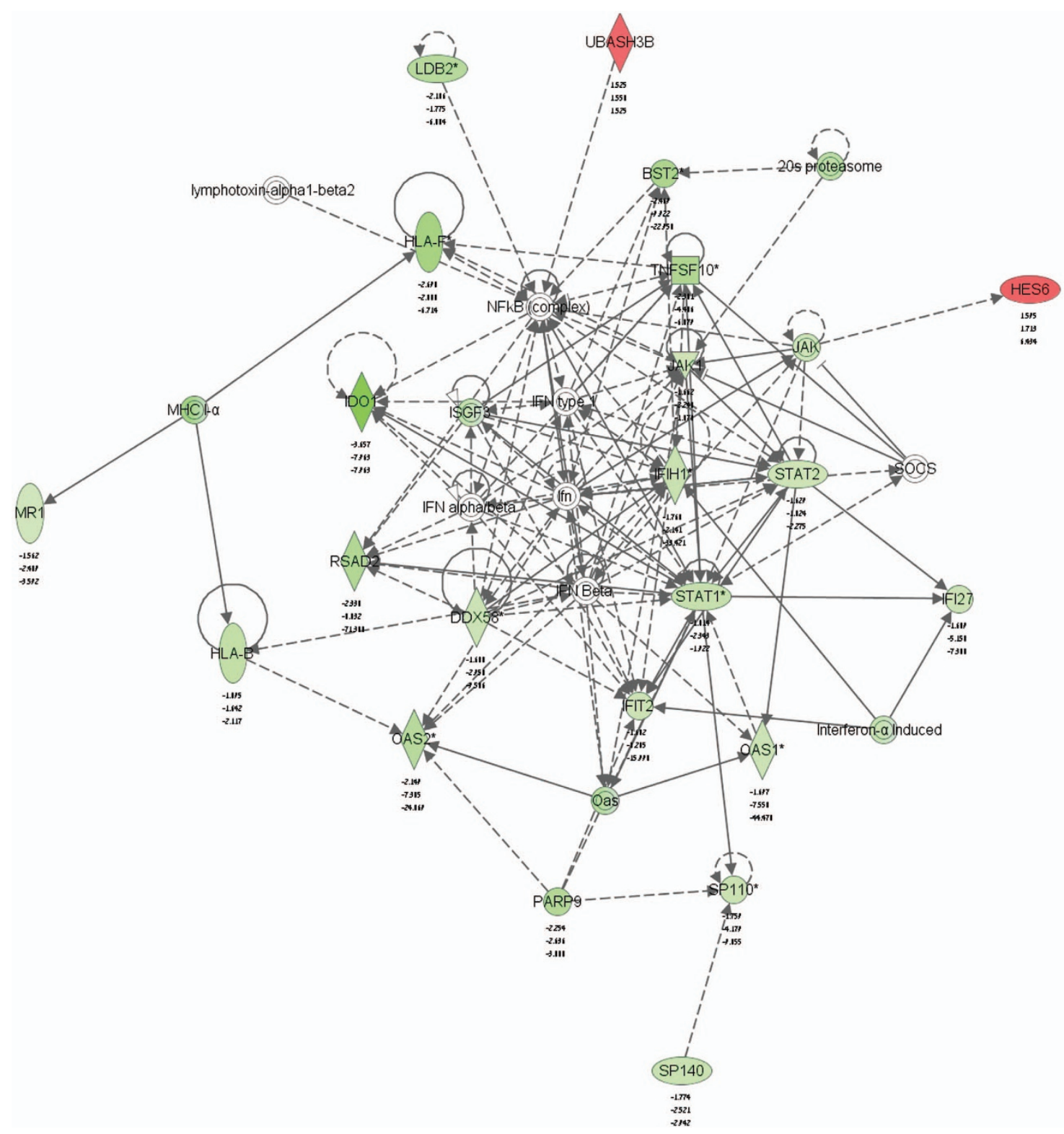

Figure 3 Network of the IFN type 1 pathway. Shown are fold decreases and increases in the expression of genes encoding the relevant enzymes relative to control (621.102 untreated cells) for each treatment. The network was produced using Ingenuity software

knockdown its expression in 621.102 cells. First, we wanted to see whether inhibition of IRF7 could mimic the change in gene expression found in the gene array (Figure 4). For that purpose, 621.102 cells were seeded in six-well plates and transfected the next day with control siRNA or siRNA against IRF7. After 72h, the mRNA levels of the indicated genes were evaluated using qRT-PCR, as described in Materials and methods section (Figure 6e). The results showed that knockdown of IRF7 has a similar effect on the gene expression as FTS or rapamycin treatment or TSC2 re-expression (Figure 6e).

In addition, 621.102 and 621.103 cells transfected with control siRNA or siRNA against IRF7 were re-seeded in 24-well plates and then counted after 3 days to assess the rate of cell growth after IRF7 knockdown. As shown in Figure 6f, cells transfected with siRNA against IRF7 proliferated significantly more slowly (by $48 \pm 4.3 \%$ in 621.102 cells) than the cells transfected with non-targeting control siRNA $(n=4$, $P<0.05$; Figure 6f). Interestingly, silRF7 knockdown had almost no effect on 621.103 cell proliferation, which strengthens the hypothesis that the observed effects of FTS, rapamycin and TSC2-re-epression are mediated by repression of IRF7 activity (Figure 6f).

To test the effect of IRF7 knockdown on cell cycle, we performed a cell cycle profile on the 621.102 and 621.103 cells after IRF7 knockdown. As shown in Figure 6g, there were no significant differences in cell cycle profile indicating that knockdown of IRF7 mimics the effect of FTS and rapamycin on cell cycle (Figure 1c).

Altogether, these accumulating data strongly suggest IRF7 is a pivotal factor in Rheb/mTOR pathway, and moreover that 
Table 2 List of selected genes altered in the gene array

\begin{tabular}{|c|c|c|c|c|}
\hline \multirow{2}{*}{$\begin{array}{l}\text { Gene } \\
\text { symbol }\end{array}$} & \multirow[t]{2}{*}{ Gene title } & \multicolumn{3}{|c|}{ Fold change } \\
\hline & & $\begin{array}{l}\text { 621.102 FTS versus } \\
621.102 \text { control }\end{array}$ & $\begin{array}{l}\text { 621.102 Rapa versus } \\
621.102 \text { control }\end{array}$ & $\begin{array}{l}621.103 \text { Con versus } \\
621.102 \text { control }\end{array}$ \\
\hline$A D M$ & Adrenomedullin & -1.5 & -1.9 & -4.3 \\
\hline APOBECЗG & $\begin{array}{l}\text { Apolipoprotein B mRNA editing enzyme, catalytic } \\
\text { polypeptide-like } 3 G\end{array}$ & -3.4 & -2.9 & -19.7 \\
\hline BST2 & Bone marrow stromal cell antigen 2 & -2.5 & -9.9 & -23.0 \\
\hline$C 3 A R 1$ & Complement component $3 a$ receptor 1 & -2.0 & -6.2 & -8.6 \\
\hline CASP1 & $\begin{array}{l}\text { Caspase 1, apoptosis-related cysteine peptidase } \\
\text { (interleukin 1, beta, convertase) }\end{array}$ & -1.9 & -3.8 & -3.3 \\
\hline$C C L 2^{\mathrm{a}}$ & Chemokine ( $\mathrm{C}-\mathrm{C}$ motif) ligand 2 & -2.0 & -1.6 & -31.6 \\
\hline COL 14A1 & Collagen, type XIV, alpha 1 & -2.5 & -2.1 & -19.3 \\
\hline $\operatorname{COL} 3 A 1^{\mathrm{a}}$ & Collagen, type III, alpha 1 & -1.6 & -1.6 & -54.9 \\
\hline$C P M$ & Carboxypeptidase M & -3.5 & -1.6 & -2.4 \\
\hline$D D \times 58$ & DEAD (Asp-Glu-Ala-Asp) box polypeptide 58 & -1.5 & -2.3 & -13.2 \\
\hline$D R A M 1$ & DNA, damage-regulated autophagy modulator 1 & -2.0 & -1.9 & -6.8 \\
\hline GBP1 & $\begin{array}{l}\text { Guanylate binding protein } 1 \text {, interferon-inducible, } \\
67 \mathrm{kDa}\end{array}$ & -2.7 & -2.1 & -8.2 \\
\hline$G B P 2^{\mathrm{a}}$ & Guanylate binding protein 2, interferon-inducible & -1.6 & -4.2 & -16.2 \\
\hline$H L A-F$ & Major histocompatibility complex class I, F & -2.5 & -2.1 & -6.4 \\
\hline HSPA5 & $\begin{array}{l}\text { Heat shock } 70-\mathrm{kDa} \text { protein } 5 \text { (glucose-regulated } \\
\text { protein, } 78 \mathrm{kDa} \text { ) }\end{array}$ & -1.5 & -6.5 & -6.1 \\
\hline ICAM1 & Intercellular adhesion molecule 1 & -1.5 & -1.6 & -3.7 \\
\hline IDO1 & Indoleamine 2,3-dioxygenase 1 & -3.7 & -8.0 & -8.0 \\
\hline IFI27 & Interferon, alpha-inducible protein 27 & -1.7 & -5.2 & -7.4 \\
\hline IFIH1 & Interferon induced with helicase C domain 1 & -1.8 & -2.1 & -33.4 \\
\hline IFIT2 ${ }^{\mathrm{a}}$ & $\begin{array}{l}\text { Interferon-induced protein with tetratricopeptide } \\
\text { repeats } 2\end{array}$ & -1.7 & -8.2 & -16.0 \\
\hline IFITM1 $1^{\mathrm{a}}$ & Interferon-induced transmembrane protein 1 (9-27) & -1.7 & -2.6 & -128.5 \\
\hline MMP3 & $\begin{array}{l}\text { Matrix metallopeptidase } 3 \text { (stromelysin } 1 \text {, } \\
\text { progelatinase) }\end{array}$ & -1.7 & -2.2 & -8.1 \\
\hline PLSCR1 & Phospholipid scramblase 1 & -2.0 & -2.6 & -13.2 \\
\hline$R S A D 2$ & Radical S-adenosyl methionine domain-containing 2 & -2.3 & -8.8 & -71.4 \\
\hline STAT $1^{\mathrm{a}}$ & $\begin{array}{l}\text { Signal transducer and activator of transcription } 1, \\
91 \mathrm{kDa}\end{array}$ & -1.8 & -4.5 & -25.5 \\
\hline TNFSF10 & Tumor necrosis factor (ligand) superfamily, member 10 & -1.8 & -5.5 & -12.8 \\
\hline TRIM22 & Tripartite motif-containing 22 & -1.8 & -1.9 & -10.0 \\
\hline TRIM5 & Tripartite motif-containing 5 & -3.0 & -2.1 & -3.3 \\
\hline$T S C 2^{\mathrm{a}}$ & Tuberous sclerosis 2 & 1.5 & 1.6 & 2.9 \\
\hline HES6 ${ }^{\mathrm{a}}$ & Hairy and enhancer of split 6 (Drosophila) & 1.6 & 1.7 & 6.4 \\
\hline$R P L 7$ & Ribosomal protein L7 & 1.6 & 2.6 & 4.5 \\
\hline
\end{tabular}

${ }^{\mathrm{a}}$ Genes that were validated using qRT-PCR

the inhibition of IRF7 activity is crucial for rapamycin or FTSmediated effect. This strongly supports the contention that IRF7 is a target in LAM and other TSC-deficiency-related pathologies, such as TSC and cancer.

\section{Discussion}

The results of this study strongly support our previous report ${ }^{14}$ that FTS inhibits the growth of TSC2-deficient rat ELT3 cells by affecting the active (GTP-bound) Rheb. In the present work, we showed that FTS can inhibit the growth not only of a rat cell line but also of a human TSC2-deficient AML cell line, which was derived from a LAM patient and can serve as a model for $\mathrm{LAM}^{27}$ (Figure 1a). This growth inhibition was similar to that induced by rapamycin (Figure 1b), since combined treatment with FTS and rapamycin yielded no additional effect beyond the effect seen by each drug alone (Figure 1d). Both drugs were selective for the TSC2-deficient cells (Figures 1a and 1b). FTS treatment decreased the levels of Rheb protein, as well as phosphorylation of its downstream target $56 \mathrm{~K}$ (Figure 1e). As we showed previously, ${ }^{14}$ FTS downregulates the level of Rheb protein by inhibiting active Rheb-GTP and reducing $\mathrm{Rheb}$ stability. As the major part of $\mathrm{Rheb}$ protein is in its GTP-bound active form, we can assume that the reduction in Rheb protein levels in the $621 \mathrm{AML}$ cells is also a result of Rheb-GTP inhibition.

We found a connection here between Rheb/mTORC1 inhibition and the IFN type 1 signaling pathway (Figure 3). Using microarray gene expression profiling of TSC2-deficient 621 AML cells, we looked specifically at overlapping genes that are altered by treatment of FTS or rapamycin or by TSC2 re-expression (Figure 2). We found that 244 and 150 genes were commonly downregulated and upregulated, respectively. Analysis of those genes showed significant enrichment of downstream targets of the IRF7 transcription factor (Figure 5), a key factor in IFN type 1-induced responses. Interestingly, the genes that were altered by FTS and rapamycin in the TSC2deficient 621.102 AML cells were not affected by those treatments in the TSC2-re-expressing 621.103 cells, indicating that the treatments were selective for the TSC2-deficient cells only (Figure 4). This suggested that inhibition of cell 

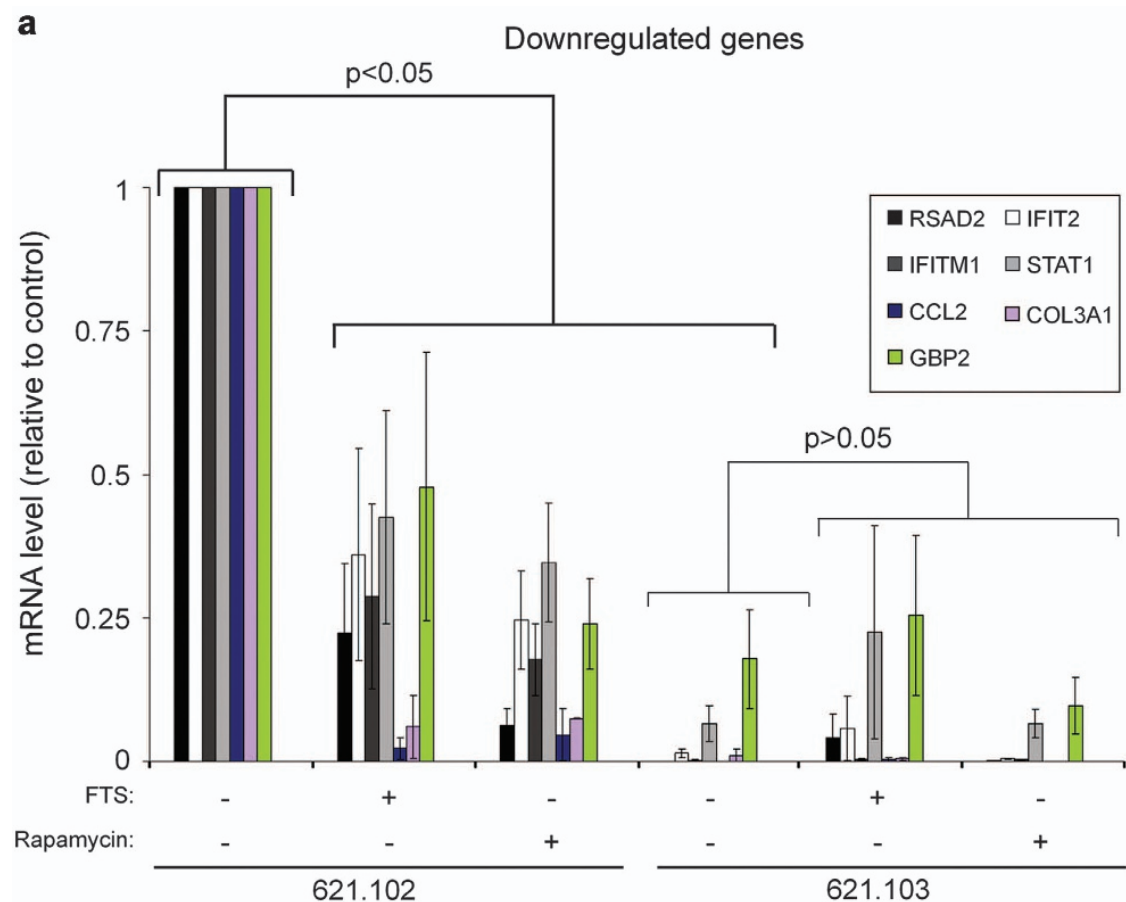

b

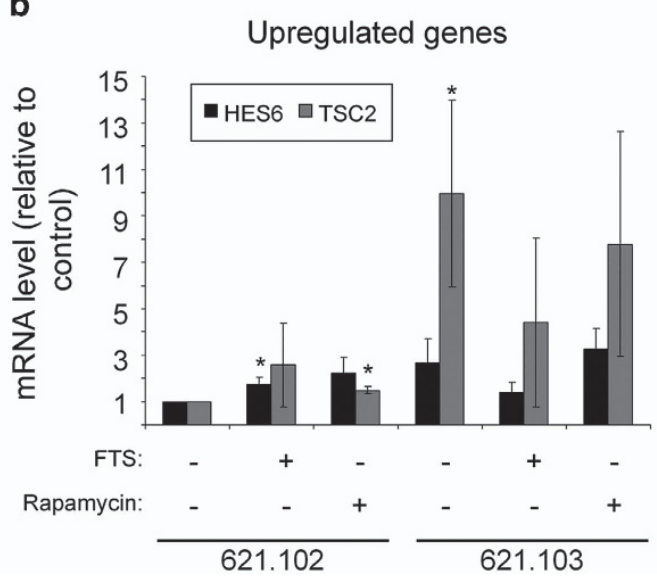

Figure 4 Validation of representative genes from the gene array using qRT-PCR. The 621.102 and 621.103 cells were treated for $48 \mathrm{~h}$ with $75 \mu \mathrm{M}$ FTS, $10 \mathrm{nM}$ rapamycin or $0.1 \% \mathrm{Me}_{2} \mathrm{SO}_{4}$ (control). The mRNA levels of the indicated genes were then quantified with specific primers by RT-PCR (see Materials and methods section). Downregulated (a) and upregulated genes (b) are shown. The results correlate with the gene array analysis (means \pm S.E.M., $n=3$ )

growth by FTS or rapamycin is dependent on activation of Rheb/mTORC1.

TSC2/mTORC1 has been shown to have an important role in the generation of IFN-induced responses. ${ }^{28}$ Moreover, gene array analysis conducted previously on TSC complex cortical tubers, also revealed a connection between mutations in TSC genes and inflammation. ${ }^{29}$ It showed elevation of inflammatory gene expression in the tumor tissue, including CCL2 and GBP1, which were also seen elevated in our study in AML cells. Other studies showed elevated levels of Stat1 in AML and LAM tissues. ${ }^{30}$ The exact mechanism leading to IFN type 1 activation is not yet known. In this study, we showed for the first time that inhibition of the Rheb/mTORC1 pathway results in a reduction in IRF7 nuclear localization (Figures 6a and 6c), which in turn decreases the transcription of IFN-stimulated genes (Figure 6e). Moreover, knockdown of IRF7 by siRNA leads to inhibition of the growth of TSC2-deficient AML cells (Figure 6f), indicating that IRF7 may be an important therapeutic target in the treatment of LAM and other TSCrelated pathologies. Previous gene expression analyses have shown that FTS can downregulate the transcription factor HIF-1a, resembling the downregulation of IRF7 in this study. ${ }^{25}$

Studies have shown that TSC2-deficient cells have a reduced sensitivity to the growth inhibitory effects of IFN- $\beta$ and that re-expression of TSC2 restores the anti-proliferative properties of this cytokine. ${ }^{31}$ Our results may explain this phenomenon, as we show here that the IFN type 1 response is heightened in TSC2-deficient AML cells independently of 


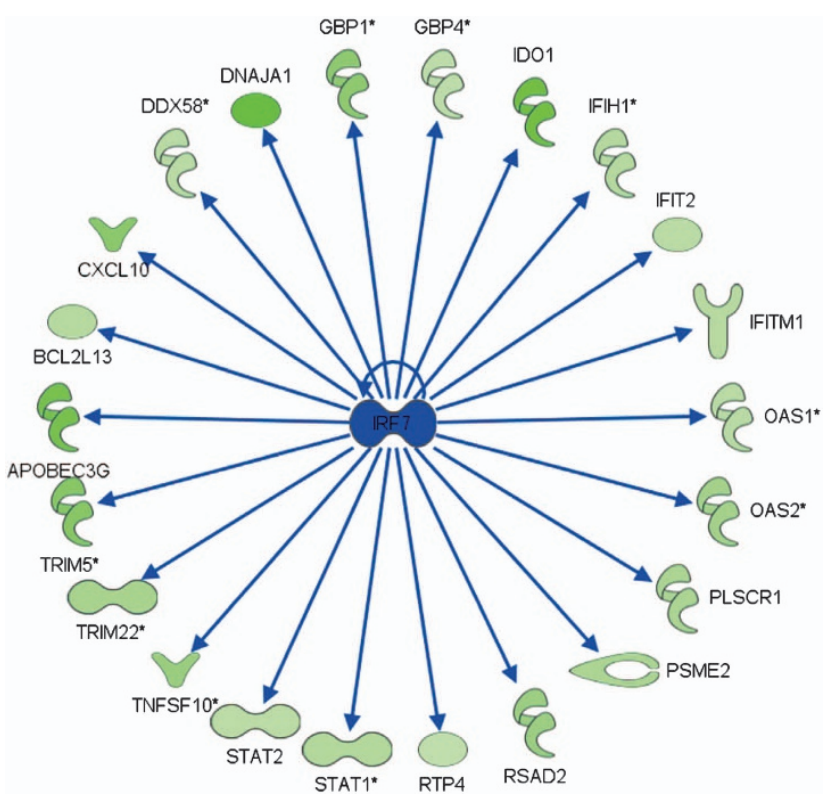

Figure 5 Scheme listing the downstream effectors of IRF7 that were downregulated in the gene array by FTS or rapamycin treatment or TSC2 reexpression. The scheme was produced using Ingenuity software

IFN- $\beta$ expression. Inhibition of the Rheb/mTOR pathway leads to reduction in IRF7 and in the IFN type 1 immune response, which may repair the cellular response to IFN- $\beta$.

Treatments currently available for LAM are poor. ${ }^{32}$ The drug leading the field in clinical trials is rapamycin (sirolimus). The problem is that prolonged treatment with rapamycin may lead to a series of adverse effects. When rapamycin treatment is discontinued, patients continue to decline. ${ }^{17}$ As this work shows that the therapeutic activity of FTS is similar to that of rapamycin, the non-toxic properties of FTS make it beneficial for the treatment of LAM. ${ }^{15}$

Studies have shown that IFN- $\gamma$ can inhibit the growth of AML lesions and that combined treatment with IFN- $\gamma$ and rapamycin yields synergistic effects. ${ }^{33}$ In light of our new results presented here, it will be interesting to test a treatment combination of FTS with IFN- $\gamma$.

\section{Materials and Methods}

Cell culture and reagents. The TSC2-null 621.101 AML cell line was derived from a kidney of a LAM patient. The 621.102 and 621.103 cell lines were stably transfected with an empty vector and TSC2 vector, respectively. ${ }^{27}$ Both cell lines were kindly provided by Dr. DJ Kwiatkowski, Brigham and Women's Hospital, Harvard Medical School, Boston, MA, USA. The cells were maintained in highglucose DMEM medium containing $10 \%$ FBS, $1 \%$ penicillin/streptomycin and $1 \%$ L-glutamine (Biological Industries, Beit HaEmek, Israel). The cells were incubated at $37^{\circ} \mathrm{C}$ in a humidified atmosphere of $95 \%$ air and $5 \% \mathrm{CO}_{2}$. FTS was a gift from Concordia Pharmaceuticals (New York City, NY, USA). Rapamycin was purchased from Sigma-Aldrich (Rehovot, Israel).

Fluorescence-activated cell sorting analysis. In all, $4 \times 10^{5}$ cells were plated per $10-\mathrm{cm}$ dish. The following day, FTS $75 \mu \mathrm{M}$, rapamycin $10 \mathrm{nM}$ or $0.1 \%$ $\mathrm{Me}_{2} \mathrm{SO}_{4}$ (control) were added and cells were incubated for $48 \mathrm{~h}$. Cells were then collected and resuspended with PBS containing propidium iodide ( $50 \mu \mathrm{g} / \mathrm{ml}$; Sigma, Rehovot, Israel) and $0.05 \%$ Triton X-100 (BDH, Arlington Heights, IL, USA) for DNA staining, then analyzed with a fluorescence-activated cell sorter (FACS Caliber; Becton Dickinson, Franklin Lakes, NJ, USA). Analysis was performed using Flowing Software (Turun Yliopisto, Finland).
Western immunoblot analysis. The 621.102 and 621.103 cells were plated at density of $4 \times 10^{5}$ cells per $10-\mathrm{cm}$ plate, grown for $24 \mathrm{~h}$, and then treated with $\mathrm{FTS}$, rapamycin or $0.1 \% \mathrm{Me}_{2} \mathrm{SO}_{4}$ (control) for $48 \mathrm{~h}$. The treated cells were lysed as described previously ${ }^{34}$ and the lysates (100 $\mu$ g protein) were immunoblotted with mouse anti-pan-Ras Ab (Calbiochem, San Diego, CA, USA), rabbit anti-Rheb $\mathrm{Ab}$ (Cell Signaling, Danvers, MA, USA), rabbit anti- $\beta$ tubulin Ab (Santa Cruz Biotechnology, Santa Cruz, CA, USA), rabbit anti-pS6K Ab, rabbit anti-S6K Ab (Sigma-Aldrich) and rabbit anti-IRF7 Ab (Abcam, Cambridge, UK). Immunoblots were exposed to the appropriate secondary peroxidase-coupled IgG $(1: 2500$ dilution, Jackson ImmunoResearch Laboratories, West Grove, PA, USA) and subjected to enhanced chemiluminescence (Amersham Pharmacia Biotech, Piscataway, NJ, USA). Protein bands were quantified by densitometry with Image EZQuant-Gel Statistical Analysis Software.

GTPase pull-down assay. Lysates containing $500 \mu \mathrm{g}$ protein were used to determine Ras-GTP content by the glutathione S-transferase Rho-binding domain pull-down assay, as described elsewhere. ${ }^{35}$

Gene expression profiling. The effect of FTS or rapamycin on gene expression in 621.102 and 621.103 cells was determined $48 \mathrm{~h}$ after treatment with FTS $(75 \mu \mathrm{M})$, rapamycin (10 $\mathrm{nM})$ or vehicle (a single microarray for each condition). The cells were lysed with TRIzol (Ambion Life Technologies, Grand Island, NY, USA) and analyzed using Affymetrix HU GENE1.0st oligonucleotide arrays (http://www. affymetrix.com/support/technical/datasheets/gene_1_0_st_datasheet.pdf).

Sample processing was performed according to the Affymetrix WT (Whole Transcript) protocol as described at (https://www.affymetrix.com/support/downloads/ manuals/wt_sensetarget_label_manual.pdf).

Analysis of gene expression data. Gene level RMA sketch algorithm (Affymetrix Expression Console, Santa Clara, CA, USA and Partek Genomics Suite 6.2, St. Louis, MO, USA) was used to generate crude data. Genes were filtered and analyzed using fold change calculations and unsupervised hierarchical cluster analysis (Spotfire DecisionSite for Functional Genomics; Somerville, MA, USA). Further processing included functional analysis and over-representation calculations based on gene ontology and published data from the Database for Annotation (GO), Visualization and Integrated Discovery (DAVID) (http://david.abcc.ncifcrf.gov/ summary.jsp) and Ingenuity Software. Data results were deposited in http://eng. sheba.co.il/genomics.

Total RNA purification and real-time PCR analysis. Total RNA was isolated using the PerfectPure RNA Cultured Cell Kit (5 Prime, Hilden, Germany) and then reverse transcribed and subjected to qRT-PCR as described previously. ${ }^{14}$ The primers used were from Real Time Primers, Elkins Park, PA, USA: human CCL2 forward, 5'-GTGTCCCAAAGAAGCTGTG-3'; human CCL2 reverse, 5'-GATT CTTGGGTTGTGGAGTG-3'; human Col3A1 forward, 5'-AGCTACGGCAATCCTG AACT-3'; human Col3A1 reverse, 5'-GGGCCTTCTTTACATTTCCA-3'; human STAT1 forward, 5'-GCAAAACCTTGCAGAACAGA-3'; human STAT1 reverse, 5'-ATCAGGGCATTCTGGGTAAG-3'; human RSAD2 forward, 5'-TCTGAAGCG AGGAGGAAAAT-3'; human RSAD2 reverse, 5'-GTTTTCAGCCACTGGGAAAT-3'; human GBP2 forward, 5'-TTTCACCCTGGAACTGGAAG-3'; human GBP2 reverse, 5'-GACGAAGCACTTCCTCTTGG-3'; human IFIT2 forward, 5'-TGGAGGAAA CCAAAATGAAA-3'; human IFIT2 reverse, 5'-TCCTCTTCACCTTCTTCACG-3'; human IFITM1 forward, 5'-AAAGCCAGAAGATGCACAAG-3'; human IFITM1 reverse, 5'-GGAGTAGGCGAATGCTATGA-3'; human TSC2 forward, 5'-GAAGTCG CAAAAACCAAGAA-3'; human TSC2 reverse, 5'-TGTGTCTCCCATTGTCTGTG-3'; human HES6 forward, 5'-CTACGGGCAGGAGGAAGAAT-3'; human HES6 reverse, 5'-AGTGCACCTGCCTCTCATCT-3'; human GAPDH forward, 5'-CCAGAACATCA TCCCTGC-3'; human GAPDH reverse, 5'-GGAAGGCCATGCCAGTGAGC-3'.

The relative mRNA expression of the target gene was normalized to the expression of the glyceraldehyde 3-phosphate dehydrogenase (GAPDH) reference gene.

Confocal microscopy. The 621.102 and 621.103 cells $\left(1 \times 10^{5}\right.$ of each) were plated on glass coverslips and treated for $48 \mathrm{~h}$ with $75 \mu \mathrm{M}$ FTS, $10 \mathrm{nM}$ rapamycin or the vehicle (control; $0.1 \% \mathrm{Me}_{2} \mathrm{SO}_{4}$ ). Cells were fixed and permeabilized as described previously. ${ }^{36}$ Cells were labeled for $1 \mathrm{~h}$ with $5 \mu \mathrm{g} / \mathrm{ml}$ rabbit anti-IRF7 Ab (Abcam) and then with 1:750 goat anti-rabbit cy3 Ab (Jackson ImmunoResearch Laboratories). The slides were incubated with Hoechst 33258 (Sigma-Aldrich) for $10 \mathrm{~min}$. Images were acquired with a Zeiss LSM 510 META confocal microscope or 


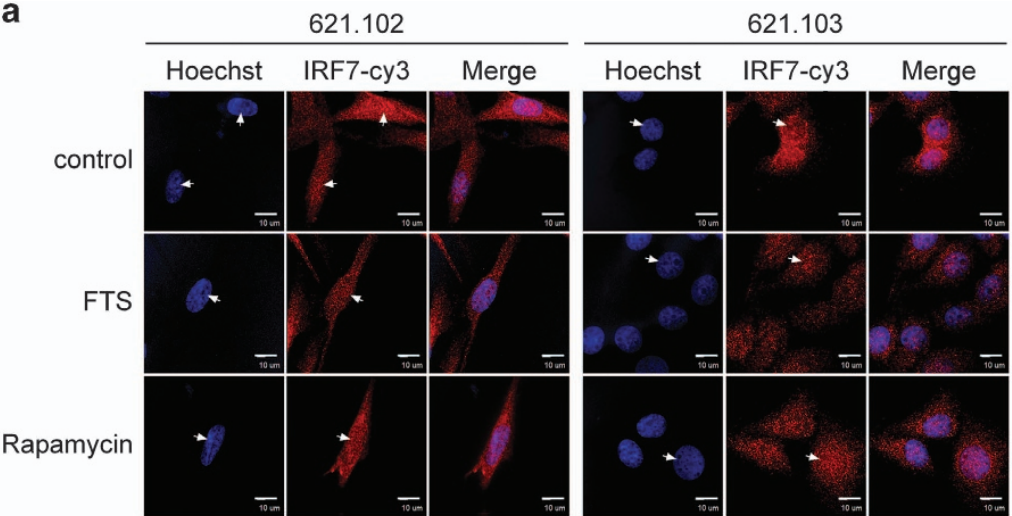

b

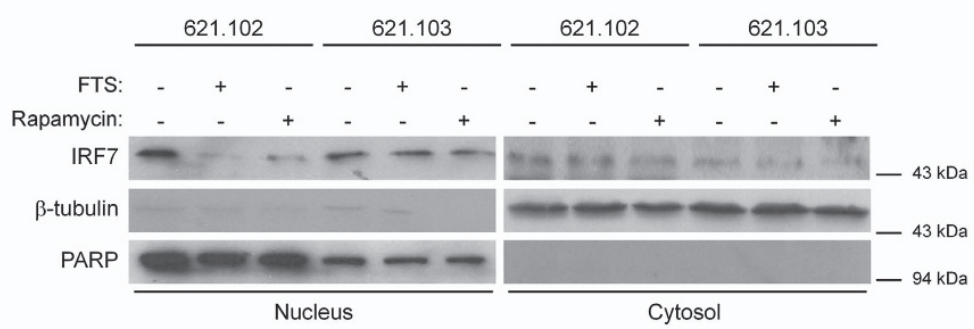

C
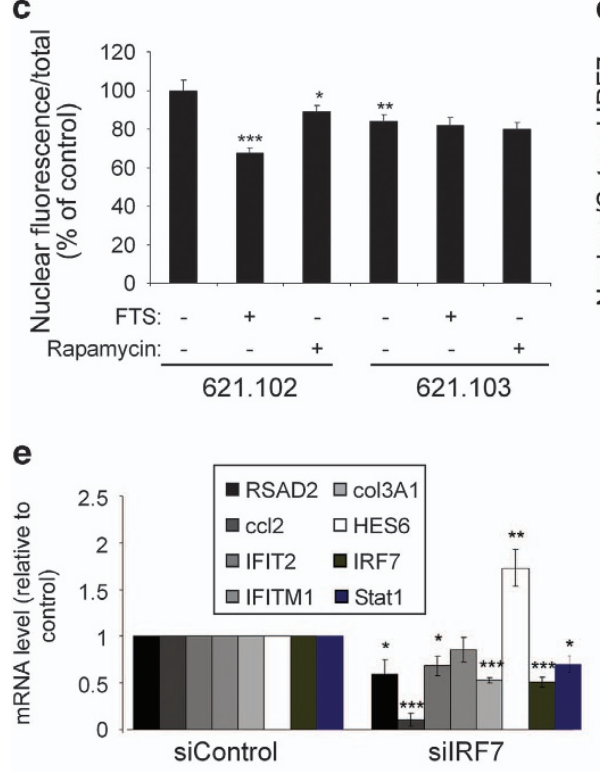

d
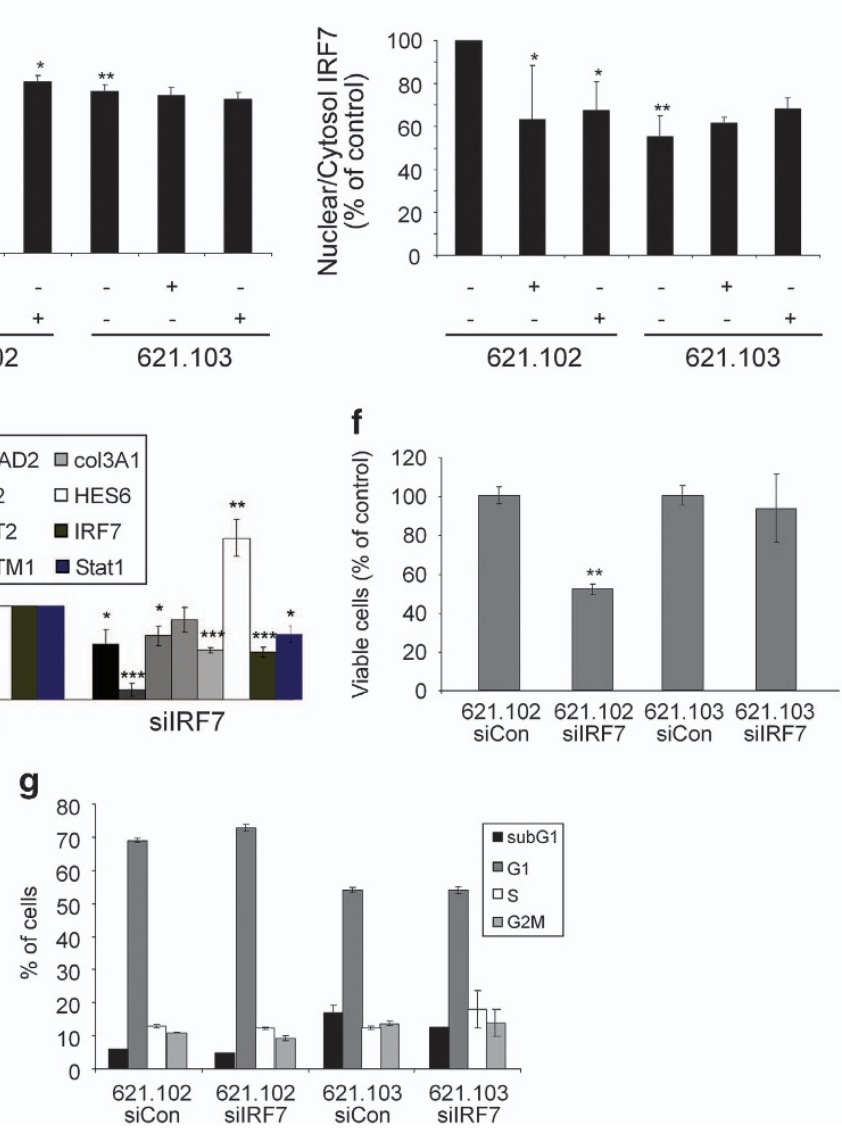

spinning-disk confocal microscope (CSU-22 confocal head (Yokogawa, Tokyo, Japan) and Axiovert $200 \mathrm{M}$ instrument (Carl Zeiss Microlmaging, Jena, Germany)) under the control of the SlideBook program (Intelligent Imaging Innovations, Denver, CO, USA), using a $63 \times$ oil immersion objective (Plan Apochromat; numerical aperture (NA), 1.4, Zeiss, Jena, Germany) and an Evolve electron-multiplying charge-coupled-device (EMCCD) camera (Photometrics, Tucson, AZ, USA). Fluorescence intensity was quantified by ImageJ software $(\mathrm{NIH}$, Bethesda, $\mathrm{MD}, \mathrm{USA})$. 
Figure 6 (a) FTS displaces the transcription factor IRF7 from the nucleus. The cells were treated similarly and then stained for confocal microscopy using anti-IRF7 Ab (see Materials and methods section). The nuclear localization of IRF7 was quantified using Hoechst staining of the nucleus (white arrow heads). Typical images of the cells are shown. (b) The cells were treated similarly and then subjected to nuclear fractionation (see Materials and methods section). IRF7 levels are shown in the nucleus and the cytosol. PARP and $\beta$-tubulin were used as nuclear and cytosolic markers, respectively, in order to show the quality of fraction separation. (c) Histograms of the IRF7 nuclear localization ratio (nuclear fluorescence/total cell fluorescence) as shown in a. FTS or rapamycin treatment or TSC2 re-expression decreased the nuclear fraction of IRF7 (means \pm S.E.M., $n=30$, ${ }^{*} P<0.05$, ${ }^{* *} P<0.01,{ }^{* *} P<0.001$ ). Similar results were obtained from three separate experiments. (d) Histograms of the IRF7 nuclear localization ratio (nuclear/cytosol intensity) as shown in b. FTS or rapamycin treatment or TSC2 re-expression decreased the nuclear fraction of IRF7 (means $\pm S$.E.M., $n=3,{ }^{*} P<0.05,{ }^{*} P<0.01$ ). (e) Knockdown of IRF7 mimics the treatment with FTS or rapamycin or re-expression of TSC2. The 621.102 cells were transfected for $72 \mathrm{~h}$ with non-targeting control or IRF7 siRNA. The mRNAs of the indicated genes were then quantified with specific primers by qRT-PCR (see Materials and methods section). Their quantified levels are shown (means \pm S.E.M., $n=3,{ }^{*} P<0.05,{ }^{* *} P<0.01,{ }^{* *} P<0.001$ ). (f) After transfection, 621.102 and 621.103 cells were re-seeded for $72 \mathrm{~h}$ and then counted to evaluate their proliferation rates. The percentage of cells relative to the control siRNA is shown. Downregulation of IRF7 reduced the proliferation rate of the 621.102 cells but did not change the proliferation rate of the 621.103 cells (means \pm S.E.M., $n=4,{ }^{* *} P<0.01$ ). (g) After transfection, 621.102 and 621.103 cells were re-seeded for $48 \mathrm{~h}$ and then fixed, $\mathrm{Pl}$ stained and subjected to FACS for cell cycle analysis (see Materials and methods section). The quantification of the different cell cycle phases is shown. No significant difference was observed after IRF7 knockdown

Nuclear fractionation. The 621.102 and 621.103 cells were plated at density of $4 \times 10^{5}$ cells per $10-\mathrm{cm}$ plate, grown for $24 \mathrm{~h}$, and then treated with FTS, rapamycin or $0.1 \% \mathrm{Me}_{2} \mathrm{SO}_{4}$ (control) for $48 \mathrm{~h}$. The treated cells were then lysed with cytosolic buffer (Hepes $10 \mathrm{mM}, \mathrm{MgCl}_{2} 1.5 \mathrm{mM}, \mathrm{KCl} 10 \mathrm{mM}$, IGEPAL $0.1 \%$, DTT $0.5 \mathrm{mM}$ and Proteinase inhibitor cocktail) and centrifuged at $960 \mathrm{~g}$ for $10 \mathrm{~min}$. The sup (cytosol) was subjected to western immunoblot. The pellet (nuclei) was washed with cytosolic buffer, resuspended with the same buffer volume as the sup and subjected to western immunoblot.

Transfection and siRNA. The 621.102 and 621.103 cells $\left(2 \times 10^{5}\right)$ were plated in six-well plates and transfected after $24 \mathrm{~h}$ with $25 \mathrm{nM}$ ON-TARGETplus IRF7 siRNA oligos, as well as ON-TARGETplus siCONTROL non-targeting pool (Thermo Scientific, Waltham, MA) using TransIT-siQUEST Transfection Reagent (Mirus, Madison, WI, USA) according to the manufacturer's instructions. As an indicator of transfected cells, we used the siGLO Green transfection indicator (Thermo Scientific). The cells were harvested after $72 \mathrm{~h}$.

Statistical analysis. Data are expressed as means \pm S.E.M.. Significant differences in mean values were assessed by Student's $t$-test. A value of $P \leqslant 0.05$ was considered significant.

\section{Conflict of Interest}

The authors declare no conflict of interest.

Acknowledgements. We are grateful to Dr. David J Kwiatkowski for the gift of the 621 cell lines. We thank Ms Shirley Smith for editorial assistance.

\section{Author contributions}

VM conceived, designed and performed research, collected and analyzed data and wrote the paper. JJ-H performed experiments and collected and analyzed data. CG-D performed experiments and collected data. BS performed experiments and collected data. ME provided facilities. GR designed research and had an important role in interpreting the results. YK conceived and designed research and wrote the paper.

1. Johnson SR. Lymphangioleiomyomatosis. Eur Respir J 2006; 27: 1056-1065.

2. Krymskaya VP. Smooth muscle-like cells in pulmonary lymphangioleiomyomatosis. Proc Am Thorac Soc 2008; 5: 119-126.

3. Henske EP, McCormack FX. Lymphangioleiomyomatosis-a wolf in sheep's clothing. J Clin Invest 2012; 122: 3807-3816.

4. Goncharova EA, Krymskaya VP. Pulmonary lymphangioleiomyomatosis (LAM): progress and current challenges. J Cell Biochem 2008; 103: 369-382.

5. Taveira-DaSilva AM, Steagall WK, Moss J. Lymphangioleiomyomatosis. Cancer Control 2006; 13: 276-285.

6. Trindade AJ, Medvetz DA, Neuman NA, Myachina F, Yu J, Priolo C et al. MicroRNA-21 is induced by rapamycin in a model of tuberous sclerosis (TSC) and lymphangioleiomyomatosis (LAM). PLoS One 2013; 8: e60014

7. Yu J, Astrinidis A, Howard S, Henske EP. Estradiol and tamoxifen stimulate LAM-associated angiomyolipoma cell growth and activate both genomic and nongenomic signaling pathways. Am J Physiol Lung Cell Mol Physiol 2004; 286: L694-L700.
8. Young LR, Franz DN, Nagarkatte $P$, Fletcher CD, Wikenheiser-Brokamp KA, Galsky MD et al. Utility of [18F]2-fluoro-2-deoxyglucose-PET in sporadic and tuberous sclerosis-associated lymphangioleiomyomatosis. Chest 2009; 136: 926-933.

9. Finlay G. The LAM cell: what is it, where does it come from, and why does it grow? Am J Physiol Lung Cell Mol Physiol 2004; 286: L690-L693.

10. Astrinidis A, Khare L, Carsillo T, Smolarek T, Au KS, Northrup H et al. Mutational analysis of the tuberous sclerosis gene TSC2 in patients with pulmonary lymphangioleiomyomatosis. J Med Genet 2000; 37: 55-57.

11. Yu J, Astrinidis A, Henske EP. Chromosome 16 loss of heterozygosity in tuberous sclerosis and sporadic lymphangiomyomatosis. Am J Respir Crit Care Med 2001; 164(8 Pt 1): 1537-1540.

12. Castro AF, Rebhun JF, Clark GJ, Quilliam LA. Rheb binds tuberous sclerosis complex 2 (TSC2) and promotes S6 kinase activation in a rapamycin- and farnesylationdependent manner. J Biol Chem 2003; 278: 32493-32496.

13. Aspuria PJ, Tamanoi F. The Rheb family of GTP-binding proteins. Cell Signal 2004; 16: 1105-1112.

14. Makovski V, Haklai R, Kloog Y. Farnesylthiosalicylic acid (salirasib) inhibits Rheb in TSC2null ELT3 cells: a potential treatment for lymphangioleiomyomatosis. Int J Cancer 2012; 130: 1420-1429.

15. Rotblat B, Ehrlich M, Haklai R, Kloog Y. The Ras inhibitor farnesylthiosalicylic acid (Salirasib) disrupts the spatiotemporal localization of active Ras: a potential treatment for cancer. Methods Enzymol 2008; 439: 467-489.

16. Parkhitko AA, Favorova OO, Khabibullin DI, Anisimov VN, Henske EP. Kinase mTOR: regulation and role in maintenance of cellular homeostasis, tumor development, and aging. Biochemistry (Mosc) 2014; 79: 88-101.

17. McCormack FX, Inoue $Y$, Moss J, Singer LG, Strange C, Nakata $K$ et al. Efficacy and safety of sirolimus in lymphangioleiomyomatosis. N Engl J Med 2011; 364: 1595-1606.

18. Savitsky D, Tamura T, Yanai H, Taniguchi T. Regulation of immunity and oncogenesis by the IRF transcription factor family. Cancer Immunol Immunother 2010; 59: 489-510.

19. Ning S, Pagano JS, Barber GN. IRF7: activation, regulation, modification and function. Genes Immun 2011; 12: 399-414.

20. Platanias LC. Mechanisms of type-I- and type-II-interferon-mediated signalling. Nat Rev Immunol 2005 May; 5: 375-386.

21. Schmitz F, Heit A, Dreher S, Eisenacher K, Mages J, Haas T et al. Mammalian target of rapamycin (mTOR) orchestrates the defense program of innate immune cells. Eur J Immunol 2008; 38: 2981-2992.

22. Hong F, Larrea MD, Doughty C, Kwiatkowski DJ, Squillace R, Slingerland JM. mTOR-raptor binds and activates SGK1 to regulate p27 phosphorylation. Mol Cell 2008; 30: 701-711.

23. Betz C, Hall MN. Where is mTOR and what is it doing there? J Cell Biol 2013; 203: 563-574.

24. Blum R, Elkon R, Yaari S, Zundelevich A, Jacob-Hirsch J, Rechavi G et al. Gene expression signature of human cancer cell lines treated with the ras inhibitor salirasib (S-farnesylthiosalicylic acid). Cancer Res 2007; 67: 3320-3328.

25. Blum R, Jacob-Hirsch J, Amariglio N, Rechavi G, Kloog Y. Ras inhibition in glioblastoma down-regulates hypoxia-inducible factor-1alpha, causing glycolysis shutdown and cell death. Cancer Res 2005; 65: 999-1006.

26. Barkan B, Kloog Y, Ehrlich M. Phenotypic reversion of invasive neurofibromin-deficient schwannoma by FTS: Ras inhibition reduces BMP4/Erk/Smad signaling. Mol Cancer Ther Aug 2011; 10: 1317-1326.

27. Siroky BJ, Yin H, Babcock JT, Lu L, Hellmann AR, Dixon BP et al. Human TSC-associated renal angiomyolipoma cells are hypersensitive to ER stress. Am J Physiol Renal Physiol 2012; 303: F831-F844.

28. Kaur S, Lal L, Sassano A, Majchrzak-Kita B, Srikanth M, Baker DP et al. Regulatory effects of mammalian target of rapamycin-activated pathways in type I and II interferon signaling. J Biol Chem 2007; 282: 1757-1768.

29. Boer K, Crino PB, Gorter JA, Nellist M, Jansen FE, Spliet WG et al. Gene expression analysis of tuberous sclerosis complex cortical tubers reveals 
increased expression of adhesion and inflammatory factors. Brain Pathol Jul 2010; 20: 704-719.

30. El-Hashemite N, Kwiatkowski DJ. Interferon-gamma-Jak-Stat signaling in pulmonary lymphangioleiomyomatosis and renal angiomyolipoma: a potential therapeutic target. Am J Respir Cell Mol Biol 2005; 33: 227-230.

31. Goncharova EA, Goncharov DA, Chisolm A, Spaits MS, Lim PN, Cesarone G et al. Interferon beta augments tuberous sclerosis complex 2 (TSC2)-dependent inhibition of TSC2-null ELT3 and human lymphangioleiomyomatosis-derived cell proliferation. Mol Pharmacol 2008; 73: 778-788.

32. El-Chemaly S, Henske EP. Towards personalised therapy for lymphangioleiomyomatosis: lessons from cancer. Eur Respir Rev 2014; 23: 30-35.

33. El-Hashemite N, Zhang H, Walker V, Hoffmeister KM, Kwiatkowski DJ. Perturbed IFN-gamma-Jak-signal transducers and activators of transcription signaling in tuberous sclerosis mouse models: synergistic effects of rapamycin-IFN-gamma treatment. Cancer Res 2004; 64: 3436-3443.

34. Elad-Sfadia G, Haklai R, Ballan E, Gabius HJ, Kloog Y. Galectin-1 augments Ras activation and diverts Ras signals to Raf-1 at the expense of phosphoinositide 3-kinase. J Biol Chem 2002; 277: 37169-37175.
35. de Rooij J, Bos JL. Minimal Ras-binding domain of Raf1 can be used as an activationspecific probe for Ras. Oncogene 1997; 14: 623-625.

36. Levy R, Biran A, Poirier F, Raz A, Kloog Y. Galectin-3 mediates cross-talk between K-Ras and Let-7c tumor suppressor microRNA. PLoS One 2011; 6: e27490.

(c) (i) Cell Death and Disease is an open-access journal published by Nature Publishing Group. This work is licensed under a Creative Commons Attribution 4.0 International Licence. The images or other third party material in this article are included in the article's Creative Commons licence, unless indicated otherwise in the credit line; if the material is not included under the Creative Commons licence, users will need to obtain permission from the licence holder to reproduce the material. To view a copy of this licence, visit http://creativecommons.org/licenses/by/4.0 